\title{
DA CRIAÇÃO DAS DEAM'S À LEI MARIA DA PENHA: \\ UMA REFLEXÃO SOBRE A QUESTÃO DA VIOLÊNCIA CONTRA AS \\ MULHERES
}

\author{
FROM THE CREATION OF THE DEAM'S TO MARIA DA PENHA LAW: \\ A REFLECTION ON THE ISSUE OF VIOLENCE AGAINST WOMEN
}

\begin{abstract}
Resumo
No espaço doméstico, os índices de violência de gênero são alarmantes e estima-se que no Brasil, mesmo após a institucionalização da Delegacia de Atendimento às Mulheres (1985) e da Lei 11.340/06 (Lei Maria da Penha), em agosto de 2006, os casos de violência doméstica praticada especialmente contra as mulheres não apresentaram queda significativa. Este trabalho propõe discutir a violência de gênero a partir de uma perspectiva cultural (especialmente abordando a questão do machismo e do patriarcalismo sob o qual a sociedade brasileira enraizou-se desde a colônia), tendo em vista os altos índices de ações violentas contra as mulheres. A pesquisa aqui apresentada está dividida em dois momentos: discussão bibliográfica sobre a temática de violência de gênero e, em seguida, análise dos últimos dados sobre violência de gênero produzidos pelo IPEA, Balanço 2013, 2014, 2015 e 2016 - Ligue 180 (Central de Atendimento à Mulher), Instituto Patrícia Galvão e SUS.
\end{abstract}

Palavras-chave: Gênero. Violência. Patriarcalismo.

\begin{abstract}
In the domestic sphere, gender violence rates are alarming and it is estimated that in Brazil, even after the institutionalization of the Bureau of Assistance to Women (1985) and Law 11.340/06 (Maria da Penha Law) in August 2006, cases of domestic violence especially against women showed no significant drop. This work aims to discuss gender violence from a cultural perspective (especially tackling the issue of machismo and patriarchy under which Brazilian society took root from colonial times), given the high rates of violent acts against women. The research presented here is divided into two stages: bibliographical discussion on the gender violence and, after that, an analysis of the latest data on gender violence produced by IPEA, Balance 2013, 2014, 2015 e 2016 - Dial 180 (Center for Assistance to Women), Institute Patrícia Galvão and SUS.
\end{abstract}

Keywords: Gender. Violence. Patriarchy.

\footnotetext{
Rosane Cristina Oliveira

Universidade do Grande Rio (UNIGRANRIO)

E-mail: rosanecrj@hotmail.com

Jacqueline de Cássia Pinheiro Lima

Universidade do Grande Rio (UNIGRANRIO)

E-mail: jpinheiro@unigranrio.edu.br

Andressa Maria Freire da Rocha Arana

Universidade do Grande Rio (UNIGRANRIO)

E-mail: dessare2015@gmail.com
} 


\section{Introdução}

As pesquisas sobre a violência de gênero, em especial a violência contra a mulher, ganharam maior repercussão a partir dos anos 1980, e passaram a constituir uma das áreas fundamentais para estudos feministas no Brasil. Estes estudos estão, também, atrelados ao processo de redemocratização brasileira e o movimento de mulheres, cujo principal objetivo era dar visibilidade às ações violentas sofridas por elas e discutir e propor intervenções sociais, jurídicas e psicológicas. Em 1985, foi inaugurada a primeira delegacia em defesa da mulher, na cidade de São Paulo. Esta delegacia foi a primeira no Brasil e no mundo. Em 2006, a Lei Maria da Penha também se tornou uma das principais políticas públicas direcionada às mulheres vítimas de violência de gênero. (Santos; Izumino, 2005)

No espaço doméstico, os índices de violência de gênero são alarmantes e estima-se que no Brasil, mesmo após a institucionalização da Lei 11.340/06, em agosto de 2006, conhecida como Lei Maria da Penha, os casos de violência doméstica praticada especialmente contra as mulheres não apresentaram queda significativa. E, além disso, a criação das DEAM's (Delegacia de Atendimento às Mulheres), em 1985, também não significaram diminuição nos casos de crimes (assassinatos, estupro, humilhações) relacionados às questões de gênero. Nos casos de violência no âmbito doméstico, o fato do homem sentir-se protetor ou proprietário da mulher, não é incomum a máxima que "em briga de marido e mulher, ninguém mete a colher" ainda fazer parte da atitude cotidiana. $O$ resultado pode ser desde o silêncio até o homicídio.

Neste sentido, este trabalho propõe discutir a violência de gênero a partir de uma perspectiva cultural e histórica (especialmente abordando a questão do machismo e do patriarcalismo sob o qual a sociedade brasileira enraizou-se desde a colônia), tendo em vista os altos índices de ações violentas contra as mulheres, mesmo após a institucionalização da Lei Maria da Penha (2006) e a criação das DEAM's (1985). É importante destacar que, neste artigo, a ênfase em relação à violência de gênero será no que diz respeito, especificamente, àquelas cometidas contra mulheres, pois, ao falarmos de violência de gênero, esta apresenta uma diversificação maior desta modalidade de violência, ou seja, abrange vítimas variadas: homens, mulheres, crianças, etc.
Oartigo está dividido em dois momentos: discussão conceitual e bibliográfica sobre a temática de violência de gênero e cultura da violência e, em seguida, análise dos últimos dados sobre violência de gênero produzidos pelo Instituto de Pesquisa Econômica Aplicada (IPEA), Balanço 2013, 2014, 2015 e 2016 - Ligue 180 (Central de Atendimento à Mulher), Instituto Patrícia Galvão, Dossiê Mulher e Sistema Único de Saúde (SUS). Nesta segunda etapa do trabalho, pretende-se chamar a atenção para o fato de que, os números alarmantes em relação à violência de gênero, espacialmente àquelas cometidas em relação às mulheres, encontram na cultura da violência, advinda do patriarcalismo e da dominação masculina, provavelmente o pior entrave para que determinadas iniciativas sociais e as políticas públicas destinadas a esta problemática encontre efetivamente resultados positivos.

\section{"Em briga de marido e mulher, ninguém mete a colher": violência de gênero, cultura da violência e patriarcalismo}

Nos últimos anos, os meios midiáticos ocupam-se em chamar a atenção para a violência contra mulher. Entre muitas discussões, algumas inflamadas e outras mais intelectualizadas, uma questão parece mais complexa de ser problematizada: o fato de que uma parcela significativa de pessoas, independente de classe social, etnia, gênero, idade, ainda partem do princípio de que "tem mulher que gosta mesmo é de apanhar". E, ainda, é possível verificar em redes sociais ${ }^{1}$, por exemplo, uma quantidade imensa de pessoas que, ao expor a "opinião", geralmente referese aos casos de violência contra as mulheres como "ela deve ter feito algo para apanhar daquele jeito", "ela não se deu ao respeito e por isso apanhou", "ela não cumpriu as obrigações de esposa e por isso ele arrumou outra", "em briga de marido e mulher ninguém mete a colher".

Procuramos, então, tentar compreender a origem da expressão "em briga de marido e mulher, ninguém

\footnotetext{
1 Nos últimos anos, especialmente nas redes sociais Facebook e Twitter, assuntos que envolvem estupros, violências físicas praticadas por cônjuges e violências contra transexuais, tem nessas páginas comentários de uma parcela significativa de "opiniões" que reforçam o posicionamento machista, violento e misógino. Um exemplo interessante são os posts polemizados na página "Moça, você é machista?" (disponível em: https:/www.facebook.com/ MocaVoceEMachista/ ), administrada por uma transexual e que se ocupa em, na maioria dos casos, expor notícias que abordam ações violentas sofridas por mulheres, entre outras violências de gênero.
} 
mete a colher". Na condição de ditado popular, pressupõese que tal expressão está enraizada ou naturalizada na cultura brasileira, o que nos remete a pensar na própria construção conceitual do termo cultura. Cultura é o elemento que traduz o modo de vida, as normas e regras, a identidade de uma determinada sociedade. Neste sentido, o termo "evolução" não se adequa quando pensamos em "mudar a cultura" de uma sociedade ou um determinado grupo social. Tal constatação está em consonância com a perspectiva de Clifford Geertz sobre a dificuldade em elaborar o conceito de cultura, uma vez que cada sociedade apresenta questões subjetivas que caracterizam sua interpretação cultural. Para Geertz (2008: 18),

A partir daí, segue-se uma peculiaridade no caminho: como simples tema de fato empírico, nosso conhecimento da cultura... culturas... uma cultura... cresce aos arrancos. Em vez de seguir uma curva ascendente de achados cumulativos, a análise cultural separa-se numa sequência desconexa e, no entanto, coerente de incursões cada vez mais audaciosas. Os estudos constroem-se sobre outros estudos, não no sentido de que retomam onde outros deixaram, mas no sentido de que, melhor informados e melhor conceitualizados, eles mergulham mais profundamente nas mesmas coisas. Cada análise cultural séria começa com um desvio inicial e termina onde consegue chegar antes de exaurir seu impulso intelectual.

Portanto, consideramos apropriado enfatizar que este artigo se alicerça na perspectiva cultural e histórica, cuja tentativa de compreensão da questão da violência contra a mulher na sociedade brasileira tem uma parcela significativa de sua origem, manutenção e dificuldade em apresentar diminuição efetiva, tanto nas bases patriarcais como na violência simbólica praticada e perpetuada ao longo do processo de socialização, quanto no processo de naturalização típicos da sociedade brasileira, cujo papel feminino subjuga-se ao do masculino. Teles (2002), ao reportar-se às discussões sobre violência de gênero, compreendida pelo movimento feminista (especialmente nos anos 1970), como violência contra mulher, afirma que:

$\mathrm{O}$ conceito de violência de gênero deve ser entendido como uma relação de poder de dominação do homem e da submissão da mulher. Ele demonstra que os papéis impostos às mulheres e aos homens, consolidados ao longo da história e reforçados pelo patriarcado e sua ideologia, induzem relações violentas entre ambos os sexos e indica que a prática deste tipo de violência não é fruto da natureza, mas sim do processo de socialização das pessoas. (Teles, 2002: 18)

A socialização é o ato de passar os elementos culturais de uma sociedade de geração para geração e, embora possamos observar algumas mudanças ao longo do tempo, é justamente o fato de que valores, regras, normas, modo de vida e formas de interpretar o mundo, demoram muito mais para apresentarem alterações. Tal constatação pode revelar algumas pistas para compreendermos a origem e a permanência da violência de gênero, e, especificamente aquela praticada contra a mulher.

\section{Sobre a violência de gênero e patriarcado}

Conceituar gênero, não necessariamente diz respeito à desigualdade entre homens e mulheres. Em geral, o aspecto da hierarquia masculina em relação ao feminino tem raízes mais profundas, transmitidas culturalmente através do patriarcalismo. ${ }^{2}$ Neste artigo, as discussões sobre a categoria gênero e violência estão pautadas nos seguintes autores: Scott (1989), Saffioti (1987; 2001; 2004), Bourdieu (2003) e Chauí (1985), entre outros. Marilena Chauí, por exemplo, aborda a violência de gênero partindo da ideia de dominação masculina, cujo resultado seria a anulação da autonomia da mulher, na condição de vítima e cúmplice de tal dominação. Heleieth Saffioti, a partir de uma perspectiva marxista do patriarcado, afirma que a violência contra a mulher está baseada no vínculo entre a dominação masculina e o sistema capitalista e racista. Para esta autora, a dominação masculina é resultante, também, da socialização machista, pois "dada sua formação de macho, o homem julga-se no direito de espancar sua mulher. Esta, educada que foi para submeter-se aos desejos masculinos, toma este destino como natural" (Saffioti, 1987: 50).

2 É importante ressaltar que a discussão não necessariamente passa, somente, pela violência contra as mulheres, mas, também, a todos que estão no universo do feminino, como, por exemplo, transgêneros e transexuais. 
É importante destacar que a discussão conceitual sobre gênero é interdisciplinar e abrange pontos de vista diversificados. A partir da perspectiva histórica, Joan Scott (1989), perpassou por uma série de estudos acerca desta categoria, apontando as lacunas que cada uma, de certa forma, deixou de preencher. Scott (1989), chama a atenção para a dificuldade das historiadoras feministas em conceituar gênero, a começar pela utilização do termo que foi lido como sinônimo de "mulheres".

Os (as) historiadores(as) feministas utilizaram toda uma série de abordagens nas análise do gênero, mas estas podem ser resumidas em três posições teóricas. A primeira, um esforço inteiramente feminista que tenta explicar as origens do patriarcado. A segunda se situa no seio de uma tradição marxista e procura um compromisso com as críticas feministas. A terceira, fundamentalmente dividida entre o pós-estruturalismo francês e as teorias angloamericanas das relações de objeto, inspira-se nas várias escolas de psicanálise para explicar a produção e a reprodução da identidade de gênero do sujeito. (Scott, 1989: 8-9)

Das três posições apresentadas por Scott (1989), neste artigo chamou-se a atenção para àquela em relação ao patriarcalismo. Para a autora o principal problema nesta proposição está no fato de que as historiadoras que aderiram às teorias do patriarcalismo enfatizaram a "subordinação" feminina a partir da "necessidade do macho dominar as mulheres". Além disso, as historiadoras que seguem esta linha de investigação, mesmo ao apresentar as diversas formas de desigualdade entre homens e mulheres, a lacuna não preenchida diz respeito à ausência de explicação de outras formas de desigualdades. A questão da diferença física entre homens e mulheres (universal e imutável) também é problemática, pois ignora fatores socioculturais.

Por outro lado, Heleieth Saffioti (2001) ao apresentar suas "contribuições feministas para o estudo da violência de gênero", do ponto de vista marxista, atribuiu ao sistema patriarcal o cerne não somente da violência de gênero, mas também a especificidade desta modalidade de violência direcionado às mulheres. ${ }^{3}$ Para Saffioti (2001: 115),

3 Para Saffioti $(2001,116)$, "violência de gênero é um conceito mais amplo, abrangendo vítimas como mulheres, crianças, e adolescentes de ambos os sexos".
No exercício da função patriarcal, os homens detêm o poder de determinar a conduta das categorias sociais nomeadas, recebendo autorização ou, pelo menos, tolerância da sociedade para punir o que se lhes apresenta como desvio. Ainda que não haja nenhuma tentativa, por parte das vítimas potenciais, de trilhar caminhos diversos do prescrito pelas normas sociais, a execução do projeto de dominação-exploração da categoria social homens exige que sua capacidade de mando seja auxiliada pela violência.

É fato que a violência de gênero, tanto homens como mulheres podem praticá-la. As mulheres podem cometer atos violentos contra seus companheiros e, recorrentemente são responsáveis, também, por exercem uma relação patriarcal com crianças e adolescentes, como afirma Saffioti. A diferença está na constatação de que "as mulheres como categoria social não têm, contudo, um projeto de dominação-exploração dos homens" (Saffioti, 2001: 116).

Além da discussão em torno da prática da violência, a violência simbólica, cuja raiz está no poder simbólico, também é um ponto interessante que nos permite interpretar não somente a violência física praticada contra mulheres, mas também, àquelas exercidas no âmbito de gestos e palavras. Neste ponto, a chamada violência simbólica é definida por Bourdieu (2001), como a modalidade de violência que é, por vezes, imperceptível por quem a comete e, também, pelos que são direta ou indiretamente afetados por ela. Isto ocorre porque tal relação faz parte de um jogo de poder, em geral naturalizado pelas partes envolvidas. Portanto, seria no poder simbólico que a violência simbólica se afirma. De acordo com Bourdieu (2004),

O poder simbólico como poder de construir o dado pela enunciação, de fazer ver e fazer crer, de confirmar ou de transformar a visão do mundo e, desse modo, a ação sobre o mundo, portanto o mundo, poder quase mágico que permite obter o equivalente daquilo que é obtido pela força (física ou econômica) graças ao efeito específico de mobilização, só se exerce se for reconhecido, quer dizer, ignorado como arbitrário. Isto significa que o poder simbólico não reside nos «sistemas simbólicos» em forma de uma «illocutionary force» mas que se define 
numa relação determinada - e por meio desta - entre os que exercem o poder e os que lhe estão sujeitos, quer dizer, isto é, na própria estrutura do campo em que se produz e se reproduz a crença. $\mathrm{O}$ que faz o poder das palavras e das palavras de ordem, poder de manter a ordem ou de a subverter, é a crença na legitimidade das palavras e daquele que as pronuncia, crença cuja produção não é da competência das palavras (Bourdieu, 2004: 14-15).

Assim, o poder simbólico, inscrito na produção das palavras, diz respeito àquele enunciado por um sujeito, uma determinada situação cujos indivíduos envolvidos retroalimentam e acreditam no que está sendo proferido. E, ainda, na afirmação de que no espaço da dominação aquele que possui poder institucionalizado pode e deve exercer poder sobre os demais. Assim, a violência simbólica, imperceptível entre os que estão envolvidos, naturalizase. Talvez, nesta abordagem esteja uma pista importante para compreendermos modalidades de violência cometida contra mulheres, que extrapolam a violência física.

$\mathrm{Na}$ ordem psicológica, por exemplo, as inúmeras formas verbais de depreciação do feminino, proferida no âmbito doméstico, se tornaram alvo de discussão e possibilitou observar traços das relações interpessoais como "relações abusivas". Em geral, neste tipo de relacionamento, as palavras direcionadas às mulheres (de forma violenta ou camuflada em ações que parecem querer protege-las), constituem o que alguns autores denominam como "abuso emocional". Straus (1979: 77), define o abuso emocional como "o uso de atos verbais e não-verbais que ferem simbolicamente outra pessoa, ou o uso de ameaças para ferir outra pessoa". Campbell (1992: 291), argumenta que o abuso emocional ocorre através de "comportamentos que podem

4 É importante esclarecer que relações abusivas podem se dar de diversas formas: entre amigos, conjugues, familiares. Neste artigo, a referência está na relação abusiva em relação àquela praticada pelos companheiros em relação às "suas" mulheres. O sentimento de posse, que perpassa pela dimensão cultural advinda do machismo enraizado na sociedade brasileira, compõe, assim, um ponto de interseção entre a violência psicológica e física sofrida pelas mulheres. Frases como: "você não conseguirá sobreviver sem a minha presença", "ninguém irá te querer além de mim", "você está louca", "você é minha mulher e não será de mais ninguém", "faço isso porque te amo", entre outras, além de diminuir a estima, também são ameaças veladas ou não, que podem chegar ao extremo, ou seja, ao assassinato tendo como motivação os anteriormente chamados de "crimes de paixão" ou "crimes passionais", que permaneceram previstos em Lei, pelo código penal de 1890 até 1940, conforme salientou Borelli (1999). ser usados para aterrorizar a vítima... que não envolvam o uso de força física". Loring (1994: 1), afirma que esta modalidade de abuso é "um processo contínuo no qual um indivíduo deprecia sistematicamente e destrói o círculo de outra pessoa. As ideias essenciais, sentimentos, percepções e características da personalidade da vítima são constantemente depreciados". Especificamente em se tratando da violência contra a mulher no âmbito familiar, as constantes palavras e ações depreciativas destinadas a elas, podem, por vezes, impedir algum tipo de reação por parte destas mulheres, seja no sentido de afastar-se do "companheiro" ou, em casos da violência emocional, seguida de violência física, a mulher denunciar aos órgãos competentes.

Dessa forma, a retomada da discussão sobre o patriarcado é interessante para compreendermos a questão da dominação masculina. E, novamente, Pierre Bourdieu, em $A$ dominação masculina, apresenta uma definição interessante:

A força da ordem masculina pode ser aferida pelo fato de que ela não precisa de justificação: a visão androcêntrica se impõe como neutra e não tem necessidade de se enunciar, visando sua legitimação. A ordem social funciona como uma imensa máquina simbólica, tendendo a ratificar a dominação masculina na qual se funda: é a divisão social do trabalho, distribuição muito restrita das atividades atribuídas a cada um dos dois sexos, de seu lugar, seu momento, seus instrumentos. (Bourdieu, 1999: 15)

No caso da sociedade brasileira, a marca inexorável da figura masculina advinda do patriarcalismo (dominador, provedor, por vezes violento, cuidador e detentor de força física e política), pode ser observado desde a literatura, na figura dos donos de engenho ou coronéis retratados, e também em novelas, séries e filmes. Além disso, a chamada cultura da violência é outra questão fundamental nesta análise.

\section{Cultura da violência e violência contra a mulher}

A violência não é apenas um ato destrutivo praticado entre os sujeitos, na forma de agressões, sejam físicas ou verbais. No caso da cultura da violência, diz respeito à violência promovida e perpetuada, ao longo do tempo e, por este motivo, nem sempre é fácil de ser observada ou modificada. Está inscrita nos ditados populares, nas "piadas" preconceituosas, mas que insistem em arrancar sorrisos de 
quem as proferem e de quem concorda com tais discursos, nos olhares, nos gestos, etc. Especificamente em se tratando da violência contra as mulheres no Brasil, o tratamento e estratégias de subalternização do feminino inscreve-se desde o período colonial. Não é intenção, neste breve artigo, discorrer sobre a colônia e o império brasileiro, mas sim chamar a atenção para o fato de que o fundamento de uma cultura de dominação do masculino em relação à mulher, no Brasil, tem raízes profundas no patriarcalismo fundado e levado adiante a partir do processo de colonização. De acordo com Tavola (1993: 7),

Em todas as classes sociais e não apenas nas mais pobres e também em família de todas as raças [...] no Brasil colônia, a mulher branca (e em geral rica) era mantida dentro de casa e lhe cabia, apenas procriar, quanto a mulher negra, como escrava, tornava-se objeto sexual dos antigos "senhores". A diferença é que as mulheres de nível econômico e social privilegiado, em geral, são mais bem informadas e conscientes de seus direitos do que as pobres - entre as miseráveis, então nem existe noções de violência.

As diversas formas de violência compõem a trama social há tempos imemoráveis e, embora justamente por sua longevidade apresente modificações em suas manifestações, está presente em todas as sociedades. Nas palavras de Ianni (2002: 8)

Não se trata de simplificar a problemática da violência, como se ela coubesse no conceito, ideia ou interpretação. Vista em toda a sua complexidade, em suas múltiplas manifestações coletivas e individuais, históricas e psicológicas, objetivas e subjetivas, é evidente que a violência é um acontecimento excepcional que transborda das várias ciências sociais; revela dimensões insuspeitadas da realidade social, ou da história, em suas implicações políticoeconômicas, socioculturais, objetivas e subjetivas. A fúria do tirano, o terrorismo de Estado, a guerra, o massacre, o escravismo, o racismo, o fundamentalismo, o tribalismo, o nazismo, sempre envolvem alegações racionais, humanitárias, ideais, ao mesmo tempo que se exercem em formas e técnicas brutais, irracionais, enlouquecidas. Em geral, a fúria da violência tem algo a ver com a destruição do "outro", "diferente", "estranho", com o que busca a purificação da sociedade, o exorcismo de dilemas difíceis, a sublimação do absurdo embutido nas formas da sociabilidade e nos jogos das forças sociais.

Entretanto, a violência contra mulher durante um longo tempo esteve atrelada à vida privada, ou seja, traduzia-se como um dos "acontecimentos" típicos da vida conjugal. Neste espaço (privado) os demais membros da sociedade e o Estado aparentemente não destinavam grandes preocupações. Até meados do século XX, apesar de uma gama significativa de estudos apontarem o protagonismo feminino, no bojo das relações socioculturais, era comum o papel da mulher atrelar-se ao lar, cuidado com os filhos e demais atividades "pouco significativas". Obviamente, esta realidade modificou-se especialmente a partir do pós-segunda guerra mundial, cujo resultado foi a inserção significativa da mulher no mercado de trabalho, e, por conseguinte, a necessidade de especialização do ponto de vista educacional. Em seguida, a pílula anticoncepcional e a questão da liberdade sexual, também contribuíram para uma mudança cultural lenta, mas significativa do papel das mulheres na sociedade. No entanto, tais transformações não parecem suficientes para que a diminuição da violência praticada contra as mulheres apresente resultados significativos, conforme demonstrado na segunda parte deste artigo.

No Brasil, as bases para definir o que é violência contra mulher foram estabelecidas em 1994, com a assinatura do documento da Convenção Interamericana para Prevenir, Punir e Erradicar a Violência contra a Mulher (Convenção de Belém do Pará). Neste documento estão impressos, além da definição do que é violência contra a mulher, também apresenta as formas que tal violência pode assumir e como se manifestam. No artigo 2 do documento, a especificação do que é violência contra a mulher é a seguinte:

Entende-se que a violência contra a mulher abrange a violência física, sexual e psicológica: a) ocorrida no âmbito da família ou unidade doméstica ou em qualquer relação interpessoal, quer o agressor compartilhe, tenha compartilhado ou não a sua residência, incluindo-se, entre outras formas, o estupro, maus-tratos e abuso sexual; b) ocorrida na comunidade e cometida por qualquer pessoa, incluindo, entre 
outras formas, o estupro, abuso sexual, tortura, tráfico de mulheres, prostituição forçada, seqüestro e assédio sexual no local de trabalho, bem como em instituições educacionais, serviços de saúde ou qualquer outro local; e c) perpetrada ou tolerada pelo Estado ou seus agentes, onde quer que ocorra. ${ }^{5}$

De acordo com a Convenção de Belém, além de definir o que é violência contra a mulher, também especificou, no artigo 7, o papel do Estado diante desta problemática:

Os Estados Partes condenam todas as formas de violência contra a mulher e convêm em adotar, por todos os meios apropriados e sem demora, políticas destinadas a prevenir, punir e erradicar tal violência e a empenhar-se em: a) abster-se de qualquer ato ou prática de violência contra a mulher e velar por que as autoridades, seus funcionários e pessoal, bem como agentes e instituições públicos ajam de conformidade com essa obrigação; b) agir com o devido zelo para prevenir, investigar e punir a violência contra a mulher; c) incorporar na sua legislação interna normas penais, civis, administrativas e de outra natureza, que sejam necessárias para prevenir, punir e erradicar a violência contra a mulher, bem como adotar as medidas administrativas adequadas que forem aplicáveis; d) adotar medidas jurídicas que exijam do agressor que se abstenha de perseguir, intimidar e ameaçar a mulher ou de fazer uso de qualquer método que danifique ou ponha em perigo sua vida ou integridade ou danifique sua propriedade; e) tomar todas as medidas adequadas, inclusivelegislativas, paramodificarouabolir leis e regulamentos vigentes ou modificar práticas jurídicas ou consuetudinárias que respaldem a persistência e a tolerância da violência contra a mulher; f) estabelecer procedimentos jurídicos justos e eficazes para a mulher sujeitada a violência, inclusive, entre outros, medidas de proteção, juízo oportuno e efetivo acesso a tais processos; g) estabelecer mecanismos judiciais e administrativos necessários para

5 Convenção Interamericana para Prevenir, Punir e Erradicar a Violência contra a Mulher (Convenção de Belém do Pará). Belém do Pará, 1994. disponível em: https://www.cidh.oas.org/basicos/ portugues/m.Belem.do.Para.htm assegurar que a mulher sujeitada a violência tenha efetivo acesso a restituição, reparação do dano e outros meios de compensação justos e eficazes; h) adotar as medidas legislativas ou de outra natureza necessárias à vigência desta Convenção. ${ }^{6}$

Neste sentido, o documento chamou a atenção para o papel fundamental do Estado, especialmente na elaboração e acompanhamento de medidas (políticas públicas) com o intuito de enfrentar os casos de violência contra as mulheres. Esta convenção foi a base da elaboração da Lei 11.340/2006, conhecida como Lei Maria da Penha. No artigo 8 da Convenção de Belém, estão as recomendações de medidas essenciais para erradicar a violência contra a mulher,

Os Estados Partes convêm em adotar, progressivamente, medidas específicas, inclusive programas destinados a: a) promover o conhecimento e a observância do direito da mulher a uma vida livre de violência e o direito da mulher a que se respeitem e protejam seus direitos humanos; b) modificar os padrões sociais e culturais de conduta de homens e mulheres, inclusive a formulação de programas formais e não formais adequados a todos os níveis do processo educacional, a fim de combater preconceitos e costumes e todas as outras práticas baseadas na premissa da inferioridade ou superioridade de qualquer dos gêneros ou nos papéis estereotipados para o homem e a mulher, que legitimem ou exacerbem a violência contra a mulher; c) promover a educação e treinamento de todo o pessoal judiciário e policial e demais funcionários responsáveis pela aplicação da lei, bem como do pessoal encarregado da implementação de políticas de prevenção, punição e erradicação da violência contra a mulher; d) prestar serviços especializados apropriados à mulher sujeitada a violência, por intermédio de entidades dos setores público e privado, inclusive abrigos, serviços de orientação familiar, quando for o caso, e atendimento e custódia dos menores afetados; e) promover e apoiar programas de educação governamentais e privados, destinados a conscientizar o público para os problemas da

6 Convenção Interamericana para Prevenir, Punir e Erradicar a Violência contra a Mulher (Convenção de Belém do Pará). Belém do Pará, 1994. disponível em: https://www.cidh.oas.org/basicos/ portugues $/ \mathrm{m}$.Belem.do.Para.htm 
violência contra a mulher, recursos jurídicos e reparação relacionados com essa violência; f) proporcionar à mulher sujeitada a violência acesso a programas eficazes de reabilitação e treinamento que lhe permitam participar plenamente da vida pública, privada e social; g) incentivar os meios de comunicação a que formulem diretrizes adequadas de divulgação, que contribuam para a erradicação da violência contra a mulher em todas as suas formas e enalteçam o respeito pela dignidade da mulher; h) assegurar a pesquisa e coleta de estatísticas e outras informações relevantes concernentes às causas, conseqüências e freqüência da violência contra a mulher, a fim de avaliar a eficiência das medidas tomadas para prevenir, punir e erradicar a violência contra a mulher, bem como formular e implementar as mudanças necessárias; e i) promover a cooperação internacional para o intercâmbio de idéias e experiências, bem como a execução de programas destinados à proteção da mulher sujeitada a violência. ${ }^{7}$

Além de medidas de ordem jurídica, o documento recomenda mudança nos padrões sociais e culturais da sociedade no que diz respeito ao processo educacional (formal e informal) destinado à homens e mulheres, bem como a necessidade de programas educacionais governamentais (judiciário e policiais) e privados, para demonstrar a importância no combate desta modalidade específica de violência. $\mathrm{O}$ incentivo e a divulgação de pesquisas que abordem a violência contra as mulheres e a interlocução com organismos de pesquisa internacionais, seria uma das medidas fundamentais para ajudar os Estados no combate à esta forma de violência.

\section{Da criação das DEAM's à Lei Maria da Penha: discussão sobre os dados da violência contra as mulheres}

As discussões em torno dos dados estatísticos sobre violência contra mulher, em geral, aparecem de forma diversificada. Por um lado, argumenta-se que os dados "parecem" alarmantes e crescentes justamente porque, "agora", as mulheres têm a seu dispor órgãos competentes para denunciar casos de violência. Por outro lado, é importante observarque, no Brasil, a criação da Delegacia de Atendimento

7 Convenção Interamericana para Prevenir, Punir e Erradicar a Violência contra a Mulher (Convenção de Belém do Pará). Belém do Pará, 1994. disponível em: https:/www.cidh.oas.org/basicos/ portugues/m.Belem.do.Para.htm à Mulher (DEAM) foi criada há três décadas e a Lei Maria da Penha ${ }^{8}$ há uma década, além de outras iniciativas por parte da sociedade civil (ONGs e demais movimentos sociais), apesar serem iniciativas que protagonizam e protagonizaram uma mudança significativa em relação aos casos de violência contra as mulheres, os números continuam alarmantes. É com base nesta constatação que afirmamos a hipótese que norteia este artigo, ou seja, de que a dificuldade em relação à diminuição dos dados acerca da violência contra as mulheres está atrelada a questão cultural e, por conseguinte, na visão e nas práticas machistas e de dominação do masculino sobre o feminino advinda e naturalizada a partir do patriarcalismo típico da sociedade brasileira. Desnaturalizar esta visão e práticas parece o maior desafio. ${ }^{9}$

De acordo com o Dossiê Mulher 2015 ${ }^{10}$, documento elaborado pelo Instituto de Segurança Pública do Rio de Janeiro (ISP), os dados em relação ao Estado

8 LEI No. 11.340/2006 - CAPÍTULO II - DAS FORMAS DE VIOLÊNCIA DOMÉSTICA E FAMILIAR - CONTRA A MULHER

Art. $7^{\circ}$ São formas de violência doméstica e familiar contra a mulher, entre outras:

I - a violência física, entendida como qualquer conduta que ofenda sua integridade ou saúde corporal;

II - a violência psicológica, entendida como qualquer conduta que lhe cause dano emocional e diminuição da autoestima ou que lhe prejudique e perturbe o pleno desenvolvimento ou que vise degradar ou controlar suas ações, comportamentos, crenças e decisões, mediante ameaça, constrangimento, humilhação, manipulação, isolamento, vigilância constante, perseguição contumaz, insulto, chantagem, ridicularização, exploração e limitação do direito de ir e vir ou qualquer outro meio que lhe cause prejuízo à saúde psicológica e à autodeterminação;

III - a violência sexual, entendida como qualquer conduta que a constranja a presenciar, a manter ou a participar de relação sexual não desejada, mediante intimidação, ameaça, coação ou uso da força; que a induza a comercializar ou a utilizar, de qualquer modo, a sua sexualidade, que a impeça de usar qualquer método contraceptivo ou que a force ao matrimônio, à gravidez, ao aborto ou à prostituição, mediante coação, chantagem, suborno ou manipulação; ou que limite ou anule o exercício de seus direitos sexuais e reprodutivos;

IV - a violência patrimonial, entendida como qualquer conduta que configure retenção, subtração, destruição parcial ou total de seus objetos, instrumentos de trabalho, documentos pessoais, bens, valores e direitos ou recursos econômicos, incluindo os destinados a satisfazer suas necessidades;

$\mathrm{V}$ - a violência moral, entendida como qualquer conduta que configure calúnia, difamação ou injúria.

(Fonte: Presidência da República - disponível em: https://www. planalto.gov.br/ccivil_03/_Ato2004-2006/2006/Lei/L11340.htm

9 Não se descarta, neste trabalho, as demais questões que permeiam tais discussões, como: raça, etnia, classe social, sexualidade, entre outros. Outra questão importante são as recorrentes notícias nos meios de comunicação sobre casos de violência contra as mulheres, especialmente os seguidos de morte, que configuram feminicídio.

10 Documento disponível em: http://arquivos.proderj.rj.gov.br/isp_ imagens/uploads/DossieMulher2015.pdf 
do Rio de Janeiro, por exemplo, ao longo de dez anos não apresentaram modificações significativas,

Em linhas gerais, os padrões de vitimização dos títulos analisados nesta edição pouco diferem dos apresentados em análises anteriores. Assim, fica mais uma vez consignada a dimensão do desafio de formular, implementar e avaliar políticas públicas eficientes para essa parcela significativa da população fluminense. As mulheres predominam como vítimas de delitos como estupro, ameaça e lesão corporal, tendo como prováveis agressores seus companheiros ou pessoas do seu convívio familiar. (ISP, 2015, p. 7)

No Dossiê Mulher $2016^{11}$ algumas categorias de análise foram incorporadas e as estatísticas em relação às modalidades de crimes cometidos contra mulheres. Neste documento estão, pela primeira vez, expostos estatisticamente, o perfil dos acusados (de acordo com o grau de escolaridade, ocupação, idade). Estes dados são importantes para repensar as punições e demais estratégias de combate da violência contra as mulheres. Outras informações relevantes fornecidas por cyberativistas e fundadoras do Movimento Mulheres Rodadas, foram utilizadas nas análises sobre assédio sexual e importunação ofensiva ao pudor.

Outro estudo interessante, de caráter nacional, foi elaborado pelo IPEA, que avaliou o impacto da Lei Maria da Penha em relação a mortalidade de mulheres por agressões. Os dados foram obtidos a partir do Sistema de Informação sobre Mortalidade (SIM) da Secretaria de Vigilância em Saúde do Ministério da Saúde (SVS/MS), no período de 2009 a 2011. Neste estudo, de acordo com as pesquisadoras Garcia et al. (2015: 251-252)

Os parceiros íntimos são os principais assassinos de mulheres. Aproximadamente $40 \%$ de todos os homicídios de mulheres no mundo são cometidos por um parceiro íntimo (4). No Brasil, foram contabilizados 19459 feminicídios no período de 2003 a 2007. De 2007 a 2011, a taxa anual de mortalidade de mulheres por agressões foi estimada em 5,22 óbitos por 100000 mulheres, o que representa aproximadamente 5000 mortes por ano.

11 Documento disponível em: http://arquivos.proderj.rj.gov.br/isp_ imagens/Uploads/DossieMulher2016.pdf
De acordo com os dados do IPEA, embora a Lei Maria da Penha tenha uma década, os índices de violência contra a mulher não sofreram grandes alterações: 2001 a 2006 - taxa de mortalidade por 100 mil mulheres - 5,28; 2007 a 2011 - taxa de mortalidade por 100 mil mulheres 5,22. Em relação à faixa etária das vítimas, são mulheres jovens (20 a 39 anos de idade), que somam $54 \%$. Cerca de $61 \%$ dos óbitos foram de mulheres negras (especialmente em regiões do nordeste [87\%]; norte [83\%]; centrooeste [68\%]). A maior parte das vítimas tinham baixa escolaridade, $48 \%$ daquelas com 15 anos ou mais tinham até 8 anos de estudo.

Para as autoras, embora o estudo realizado apresente limitações, uma vez que alguns dados não são exigidos pela SIM (como que tipo de relação existia entre o agressor e a vítima), a intenção foi discutir o feminicídio de forma mais ampla.

A impossibilidade da identificação da relação entre vítima e agressor também poderia ser considerada uma limitação. Todavia, há que se destacar que este não foi um objetivo do estudo e que a definição de feminicídio adotada foi a mais ampla. A obtenção de informações acuradas sobre feminicídios e sua relação com a violência de gênero é um desafio, pois, na maioria dos países, assim como no Brasil, os sistemas de informação sobre mortalidade não documentam a relação entre vítima e perpetrador, nem os motivos da morte por agressão. Conhecer essa realidade é importante para subsidiar e avaliar políticas públicas, não havendo dúvidas de que informações mais detalhadas são necessárias. (Garcia et al., 2015: 255)

A pesquisa realizada por Julio Jacobo Waiselfisz, intitulada Mapa da Violência 2012 - Atualização: homicídio de mulheres no Brasil, promovida pela (Faculdade Latino Americana de Ciências Sociais do Brasil (FLACSO Brasil), discute dados de homicídios e demais modalidades de violência contra as mulheres, e novamente, constata-se que apesar das políticas públicas existentes até o momento, as taxas de feminicídio, agressões variadas cometidas contra mulheres no Brasil, continuam crescentes. Os dados foram obtidos a partir dos números apresentados pelo Sistema Único de Saúde (SUS). Para Waiselfisz (2012), "68\% dos atendimentos a 
mulheres vítimas de violência, a agressão aconteceu na residência da vítima", $42 \%$ do número total de agressões foi promovida por parceiros ou ex-parceiro das vítimas, especialmente entre as mulheres na faixa etária entre $20 \mathrm{e}$ 49 anos (neste caso, somam 65\% das agressões).

Os mecanismos pela qual essa tolerância atua em nosso meio podem ser variados, mas um prepondera: culpabilização da vítima como justificativa dessa forma de violência, foi a estuprada quem provocou o incidente, ou ela vestia como "vadia”. Nesse processo, o adolescente vira marginal, delinquente, drogado, traficante. A própria existência de leis ou mecanismos específicos de proteção: estatutos da criança, adolescente, idoso; Lei Maria da Penha, ações afirmativas, etc. indicam claramente a desigualdade e vulnerabilidade real desses setores; se no ano seguinte à promulgação da Lei Maria da Penha, em setembro de 2006, tanto o número quanto as taxas de homicídio de mulheres apresentou uma visível queda, já a partir de 2008 a espiral de violência retoma os patamares anteriores, indicando claramente que nossas políticas ainda são insuficientes para reverter a situação. (Weiselfisz, 2012)

Esta constatação, assinalada por Weiselfisz (2012), remete-nos a pensar não somente em relação à necessidade de políticas públicas mais eficazes, mas também no fato de que a violência contra mulher, perpetuada culturalmente na sociedade brasileira, é um dos entraves para a reversão dos dados estatísticos. Apesar, por exemplo, do uso de tecnologias de vigilância tanto no ambiente doméstico como em espaços públicos, com o intuito de coibir atos violentos diversos, muitas agressões, seguido de assassinato são cometidos por parceiros ou exparceiros. Parece, portanto, que o medo da punição não exerce eficácia. Nestes casos, pode-se argumentar que o poder exercido pelo masculino (a dominação masculina) naturalizado do ponto de vista cultural, prevalece e inibe a ação eficaz das esferas políticas e jurídicas.

Sobre a violência doméstica, ou seja, aquela que acontece dentro do espaço familiar, é a que mais atinge as mulheres. Segundo Almeida et al. (2003: 27),

A vítima de violência doméstica, geralmente tem pouca auto-estima e se encontra atada na relação com quem a agride, seja por dependência emocional ou material. $\mathrm{O}$ agressor geralmente acusa a vitima de ser responsável pela sua agressão a qual acaba sofrendo uma grande culpa ou vergonha. A vitima também se sente violada e traída, já que o agressor promete que depois do ato, nunca mais vai repetir este tipo de comportamento, para depois repeti-lo. (Almeida et al., 2003: 27)

Em agosto de 2014, o jornal O Globo publicou uma matéria apontando os dados do disque 180, telefone de denúncias da Secretaria Nacional de Política para Mulheres (SPM), destacando a agressão física como a principal forma de violência contra mulher. De acordo com a reportagem:

Os relatos feitos ao Disque 180, telefone de denúncias da Secretaria Nacional de Política para Mulheres (SPM), mostram que $25 \%$ das vítimas sofrem violência desde o início da relação. O período em que ficam expostas é longo: em 38\% dos casos, o tempo de relacionamento chega a dez anos. Mesmo depois da Lei Maria da Penha, as mulheres demoram a denunciar por medo de serem mortas ou por vergonha. - O fim do relacionamento é um momento de risco para a mulher. Muitos assassinatos ocorrem com o rompimento - diz Aline Yamamoto, coordenadora de Acesso à Justiça e Combate à Violência da SPM. Ainda hoje os tribunais abrandam a pena aplicada aos autores desse tipo de crime, sob argumento de que foi cometido sob "forte emoção". - Não são crimes passionais. São crimes de ódio cometidos com requintes de crueldade, com mutilações do corpo feminino ressalta Aline. $^{12}$

O Balanço 2014 - ligue 180, apresentou os seguintes dados: Em 2014, do total de 52.957 relatos de violência contra a mulher, 27.369 corresponderam a relatos de violência física (51,68\%), 16.846 de violência psicológica (31,81\%), 5.126 de violência moral $(9,68 \%), 1.028$ de violência patrimonial (1,94\%), 1.517 de violência sexual (2,86\%), 931 de cárcere privado $(1,76 \%)$ e 140 de tráfico de pessoas $(0,26 \%)$. Em comparação com 2013, a Central de Atendimento à Mulher constatou que, no tocante aos relatos de violência, em 2014 houve aumento de $50 \%$ nos registros de cárcere privado,

12 Reportagem na íntegra disponível em: http:/oglobo.globo.com/ brasil/agressao-fisica-encabeca-violencia-contra-mulher-12866926 
numa média de 2,5 registros/dia, e de $18 \%$ nos casos de estupro, numa média de três denúncias/dia. $\mathrm{O}$ relato de violência sexual contra mulheres - estupros, assédios e exploração sexual - cresceu $20 \%$ em 2014, numa média de quatro registros/dia.

\section{Em 2015, 76.651 (10,23\% dos atendimentos)} foram referentes à violência, e mais da metade, $58,86 \%$ diziam respeito à casos de violência contra mulheres negras. Esta constatação, de acordo com o relatório, demonstra a necessidade da inclusão das categorias de ração e gênero nos registros de violência contra a mulher. Até o ano de 2015, tais categorias não apareceriam explicitadas no relatório e, portanto, tornava difícil verificar e analisar os dados de violência contra mulheres tendo como elemento fundamental a questão étnica. Outra questão verificada no relatório de 2015 são os dados alarmantes no que concerte à denúncia de violência física $(50,16 \%)$ e violência psicológica (30,33\%). No primeiro semestre de 2016, foram registrados 67.962 relatos de violência contra mulheres e, destes, $86,64 \%$ estavam devidamente tipificados na Lei Maria da Penha.

Em 2016, um dado interessante é destacado no relatório: mais de 30\% das ligações foram registrados por pessoas próximas às vítimas, o que denota a possibilidade de mudança de perspectiva em relação à violência contra mulheres. Talvez, o ditado popular "em briga de marido e mulher ninguém mete a colher", deixe aos poucos de fazer parte do imaginário social. E, ainda, nos casos de violência doméstica, na maioria dos casos possuem filhos e estes assistem ou, também, são vítimas de violência.

O avanço legislativo também tem contribuído para uma maior conscientização da sociedade sobre o fenômeno da violência de gênero, dado que cada vez mais amigos/ as, familiares e vizinhos/as ligaram para o Ligue 180 a fi m de relatar situações de violência sofridas por mulheres. No primeiro semestre de 2016, 32\% dos relatos não foram registrados pelas próprias vítimas, mas por pessoas próximas. Os atendimentos registrados no $1^{\circ}$ semestre de 2016 pelo Ligue 180 revelaram que $78,72 \%$ das vítimas de violência doméstica possuem filhos/as e que $82,86 \%$ desses(as) filhos(as) presenciaram ou sofreram violência. Esses dados apontam para uma triste realidade - a violência de gênero que marca, mutila e mata milhares de brasileiras no âmbito doméstico e familiar, acomete também seus/suas filhos/as. ${ }^{13}$

No âmbito das políticas públicas, especialmente a atuação das DEAM's e a Lei Maria da Penha, é fato que tais propostas são fundamentais. Entretanto, neste trabalho, enfatiza-se que por ser um elemento construído (também) culturalmente e naturalizado na sociedade brasileira, a violência contra mulher, assim como outros temas chamados "transversais"14 já participantes dos currículos escolares, pode ser incorporada nas discussões nos espaços educacionais, em todos os níveis, bem como outros lugares de sociabilidade (institucionalizados ou não). A problematização constante desta temática pode gerar na sociedade elementos que configurem mudança social e, portanto, ajudar na eficácia das iniciativas por parte do Estado.

\section{Considerações finais}

Ao longo deste artigo, a discussão baseou-se em dois momentos: o primeiro discutindo conceitualmente violência de gênero e cultura violência, com o intuito de tentar compreender a especificidade da violência contra a mulher (na condição de uma das modalidades de violência de gênero). Nesta etapa, as discussões sobre patriarcalismo levantadas por Heleieth Saffioti e Joan Scott, entre outros, foram fundamentais. Já nas questões que envolvem as formas de violência praticada contra as mulheres, a leitura de Pierre Bourdieu sobre violência e poder simbólico e a dominação masculina, foram elucidativos para chamar a atenção em relação aos casos dos chamados "relacionamentos abusivos" praticados, especialmente, no âmbito doméstico pelos parceiros das vítimas. Fato este comprovado nos dados das pesquisas comentados na segunda parte deste artigo.

A principal constatação do estudo apresentado está

13 Balanço 180 - 2016 - Central de Atendimento à Mulher, p. 3. (Disponível em: http://www.spm.gov.br/balanco180 2016-3.pdf)

14 Podemos destacar, por exemplo, as discussões sobre racismo, intolerância religiosa, entre outros, que apresentam inúmeras discussões acadêmicas e midiáticas, mas no âmbito das mudanças de comportamento no bojo da sociedade, a lentidão ainda é fato. A maior prova disso são os dados que apontam números alarmantes de homicídios cometidos contra jovens negros, conforme podemos observar nos dados da Anistia Internacional. De acordo com esses dados, em 2012, aproximadamente 56.000 jovens foram assassinados no Brasil, entre os quais, 77\% eram negros. (Ver: https://anistia.org.br/ campanhas/jovemnegrovivo/). 
na afirmação de que os índices de violência de gênero, em especial àqueles praticados contra a mulher não obtiveram regressão efetiva, se observarmos os dados (IPEA, Disque 180, Instituto Patrícia Galvão, SUS, Dossiê Mulher 2015 e 2016) a partir de meados dos anos 1980. Ainda que o Estado tenha promovido algumas políticas públicas importantes para as mulheres, como a criação das DEAM's, em 1985 e a promulgação da Lei Maria da Penha, em 2006, as práticas de violência contra a mulher enraizadas no machismo e no patriarcalismo, culturalmente assimilados no Brasil, impedem as mudanças de mentalidades em relação a esta modalidade de violência.

\section{Referências Bibliográficas}

ALMEIDA, Caroline Ascênio et al. (2003). Consequências do abuso sexual intrafamiliar. 2003. 106 f. Monografia (Bacharelado em Serviço Social) - Faculdades Integradas “Antônio Eufrásio de Toledo”, Presidente Prudente.

BORELLI, Andrea. (1999). Matei por amor: representações do masculino e do feminino nos crimes passionais. São Paulo: Celso Bastos Editor.

BOURDIEU, Pierre. (1999). A dominação masculina. Rio de Janeiro: Bertrand Brasil, 1999.

CAMPBELL, Joseph. (1992). O Herói de Mil Faces. São Paulo: Cultrix.

CARDOSO, Ruth; PAOLI, Maria Célia; SOS-MULHER (Orgs.). (1985). Perspectivas Antropológicas da Mulher, vol. 4. Rio de Janeiro: Zahar Editores.

CHAUÍ, Marilena. (1985). "Participando do debate sobre mulher e violência". In: CHAUÍ, Marilena. Participando do Debate sobre Mulher e Violência. In: CARDOSO, Ruth, et al Perspectivas Antropológicas da Mulher $n^{\circ}$ 4, Rio de Janeiro, Zahar.

GARCIA LP, Freitas LRS, Silva GDM, Höfelmann DA. (2015). "Estimativas corrigidas de feminicídios no Brasil, 2009 a 2011". Rev Panam Salud Publica. 37(4/5):2517. Disponível em: http://www.compromissoeatitude. org.br/wp-content/uploads/2015/07/GARCIA_ estimativasfeminicidios2015.pdf $>$. Acesso em: 8 jun. 2015.
GEERTZ, Cliford. (2008). A interpretação das Culturas. Rio de Janeiro: LTC.

IANNI, Octávio. (2002). "Violence in contemporary society". Estudos de Sociologia, Araraquara, n.12, p. 7-28. (versão em português disponível em: http://seer. fclar.unesp.br/estudos/article/viewFile/644/647) Acesso em: 10/jun. 2015)

Instituto de Segurança Pública (RJ). (2015). Dossiê mulher 2015 / organização: Andréia Soares Pinto, Orlinda Cláudia R. de Moraes, Joana Monteiro. - Rio de Janeiro: Instituto de Segurança Pública. Disponível em: $<$ http://arquivos.proderj.rj.gov.br/isp_imagens/uploads/ DossieMulher2015.pdf $>$. Acesso em: 18 set. 2015.

Instituto de Segurança Pública(RJ). (2016). Dossiê mulher 2016 / organização: Andréia Soares Pinto, Orlinda Cláudia R. de Moraes - Rio de Janeiro: Instituto de Segurança Pública. Disponível em: <http://arquivos.proderj.rj.gov. br/isp_imagens/Uploads/DossieMulher2016.pdf $>$. Acesso em: 19 mai. 2017.

LORING, M. T. (1994). Emotional abuse. New York: Lexington Books.

SAFFIOTI, Heleieth. (1987). O poder do macho. São Paulo: Moderna. (Coleção Polêmica).

(2001). "Contribuições feministas para o estudo da violência de gênero". Cadernos Pagu (16). P. 115-136. . (2004). Gênero, Patriarcado, Violência. São Paulo: Editora Fundação Perseu Abramo.

SANTOS, Cecília MacDowell; e IZUMINO, Wânia. (2005). "Violência contra as Mulheres e Violência de Gênero: Notas sobre Estudos Feministas no Brasil". In E.I.A.L. Estudios Interdisciplinarios de América Latina y El Caribe, vol. 16, no 1: 147-164.

SCOTT, Joan. (1989). Gender: a useful category of historical analyses. Gender and the politics of history. New York, Columbia University Press. 
STRAUS, M. A. (1979). "Measuring intrafamily conflict and violence: the conflict tactcs (CT) scales". Journal of Marriage and the Family. V. 41. Menasha. P. 75-88.

TÁVOLA, A. (1993). A violência contra a mulher. Centro de documentação e informação: Brasília.

TELLES, Inocêncio Galvão. (2002). Manual dos contratos em geral. 4. ed., Atual. Coimbra: Coimbra Ed.

Data de recebimento: 23/08/2017.

Data de aceitação: 20/12/2017. 